\title{
Clinicoepidemiological Pattern of Rhinosinusitis in a University Hospital in Ekiti, Nigeria
}

\author{
Adegbiji Atilade Waheed ${ }^{1}$, Aremu Shuaib Kayode ${ }^{2 *}$, Akanbi Ganiyu Olusola ${ }^{3}$, Olatoke Fatai ${ }^{4}$ and Ajite Kayode \\ Olumide ${ }^{5}$
}

${ }^{1}$ ENT Department, Ekiti State University Teaching Hospital, Africa

${ }^{2}$ ENT Department, Federal Teaching Hospital, Ido-Ekiti, Africa

${ }^{3}$ Radiology Department, Ekiti State University Teaching Hospital, Africa

${ }^{4}$ ENT Department, Federal Medical Centre,Lokoja,Kogi State.Nigeria

${ }^{5}$ Opthalmology Department Ekiti state university teaching hospital, Ado-Ekiti.Nigeria

Submission: January 02, 2018; Published: January 09, 2018

*Corresponding author: Shuaib K Aremu, ENT Department, Federal Teaching Hospital, Ido-Ekiti, Africa, Tel: +23480333583842;

Email: shuaib.aremu@gmail.com

\section{Abstract}

Background: Rhinosinusitis is a common sinonasal disease worldwide. This study aimed at determining the epidemiological and clinical patterns of rhinosinusitis among Ekiti community in Nigeria.

Materials and Methods: This is a prospective hospital based study of rhinosinusitis in Ekiti state university teaching hospital, Ado Ekiti, Nigeria. The study was carried out in our ear, nose and throat clinic over a period two years. Detailed clinical history, examination and investigation. In this study, the symptoms-based diagnosis of rhinosinusitis was made to diagnosed and classified the participants into acute or chronic rhinosinusitis using interviewers assisted questionnaire. Data obtained were collated and analyzed using SPSS version 18.

Results: There were 523 consented patients with rhinosinusitis enrolled into the study. Prevalence in this study was $8.3 \%$. There were $51.6 \%$ males and $48.4 \%$ females. Male to Female ratio was 1:1. Major presenting complaints were nasal discharge 79.7\%, nasal obstruction/stuffiness $76.9 \%$, and bouts of sneezing in $47.6 \%$. Clinical findings were eodematous nasal mucosa $72.8 \%$, enlarged turbinate $67.1 \%$ and reduced nasal patency $52.9 \%$. Majority $77.6 \%$ were chronic rhinosinusitis while $22.4 \%$ were acute rhinosinusitis at presentation.

Quality of life is affected in $81.0 \%$ of the total studied population. They were further analyzed as sleep disturbances $37.4 \%$, bodyache $24.5 \%$, general health $16.1 \%$, anxiety $12 . .6 \%$, fatigue $4.8 \%$ and sexual dysfunction $7.2 \%$. Major comorbid illnesses were nasal polyps $24.8 \%$ and asthma $19.5 \%$. Associated complications of the rhinosinusitis were mainly pharyngitis $35.1 \%$ and otitis media $31.9 \%$. Microscopic, culture and sensitivity revealed growths of streptococcus $24.1 \%$ and Staphylococcus aureus $18.5 \%$. The radiological (CT scan and plain x ray) findings on the paranasal sinuses revealed $86.3 \%$ different forms of abnormalities in the nasal cavity and paranasal sinuses. These were mostly maxillary sinus. Medical therapy was offered to $76.3 \%$ while surgical therapy was offered to $23.7 \%$. Remarkable improvement was noticed by $87.2 \%$ of the participants.

Conclusion: Rhinosinusitis is a common sinonasal disease with prevalence of $8.4 \%$ in Ekiti. The commonest type is allergic rhinosinusitis. However, this diseases impact upon the quality of life such as sleep, work, school, and so on.

Keywords: Rhinosinusitis; Allergic rhinitis; Co-morbidities; Quality of life; Lund-Mackay ct scoring

\section{Introduction}

Nose and paranasal sinuses are uppermost component of air passage encased in facial bone. The paranasal sinuses, four paired developed as out-pouches of the nasal cavities into facial bone which they bare their names. The mucosa lining of the paranasal sinuses, air filled was continuous with that of the nasal cavities through their ostia [1-3]. Rhinosinusitis is defined as inflammation of the mucosa lining of the nose and the paranasal sinuses. This disease is strictly restricted to the mucosa lining but once this mucosa lining is bridged it is said to be complicated rhinosinusitis $[4,5]$. This condition arises from reactive or infective agents. Reactive condition such as allergy and infective condition such as viral, bacterial and fungal [6,7]. Epidemiologically rhinosinusitis is a common household's disease worldwide. However, the prevalence varies depending on the studied population. Studies in developed countries show different prevalence of rhinosinusitis results. It is important to note that rhinosinusitis occurs worldwide and affects about $16 \%$ of the adult American population annually significantly impairing their quality of life $[8,9]$.

Rhinosinusitis is also a very common disease in Southeast Asia and also in Latin American countries [8,9]. In the pathogenesis of rhinosinusitis the most common precursor to bacterial rhinosinusitis is the viral infection of upper respiratory 


\section{Global Journal of Otolaryngology}

tract. Rhinosinusitis may also arise from sinus obstruction from mucosal oedema following inhalation of allergens [6-8]. Superimpose bacterial or fungal infection may follows. Poor or delayed treatment, virulent microorganisms or low immune status of infected person leads to bridge of sinonasal mucosa and extension to contiguous structures. Complications such as orbital, cranial, pharyngeal, otological extension may arise. Rhinosinusitis clinical features depend on factors such as duration of illness, offending organism, associated complication. Rhinosinusitis typical clinical presentations includes nasal discharge, facial pain, nasal obstruction, itching (nose, eyes, throat, ear), excessive sneezing, smell abnormalities, headache, halitosis, hawking and symptoms of the complications [6-9].

Adequate evaluation of patients with rhinosinusitis is very crucial before treatment. It is important to identify implicating microorganisms such viral, bacterial or fungal infection. This studies determined appropriate antibiotics to be administered $[10,11]$. The extent and level of extension of the rhinosinusitis in the nose and paranasal sinuses with their surrounding organ can be determined by appropriate imaging. They range from simple, cheap, and less diagnostic value plain $\mathrm{x}$ ray to most expensive, and more diagnostic value such as computerized tomographic (CT) scan and magnetic resonance imaging (MRI) [12]. Radiological examination is of great importance in surgical planning of the patients. To determine extent and type of sinonasal surgery to be employed. Rhinosinusitis despite been common in our environment like other parts of the world, there is paucity of literature on this subject in Nigeria from Ekiti, South West Nigeria. The otorhinolaryngologist must note that more advanced rhinosinusitis cases are likely to present to the primary care physician before referral to the specialist in bad shape. This study aimed at determining the epidemiological and clinical patterns of rhinosinusitis among the Ekiti community, south west Nigeria.

\section{Materials and Methods}

This is a prospective study of the patients with clinical diagnosis of rhinosinusitis seen, reviewed and managed in the Ear, Nose and Throat department of the Ekiti State University Teaching Hospital, Ado Ekiti, Nigeria. This is the only state owned tertiary health facility serving over two millions populations. The study was carried out over a period of two years (from February 2015 to January 2017). All consecutive patients who presented to the department were enrolled into the study. Ethical clearance was sought for and obtained from the ethical committee of the hospital. Informed consent was obtained from patients/guardian/parents before patients were enrolled into the study. These consented patients were then prospectively studied. Interviewer assisted questionnaire were given to consented patient to obtain detailed history on biodata, and occupation. Detailed otorhinolaryngological history was taken from the patient/guardian/parents. Detailed history on possible aetiological and predisposing factor for rhinosinusitis was taken. Past medical, surgical, family and social history were taken. General physical and systemic examination was performed.
Thorough nose, ear, throat, head and neck examination were done and documented. Thorough rhinological examination includes anterior rhinoscopy, nasal cavity and posterior rhinoscopy with nasoendoscopy. Oropharyngeal examination performed and findings were documented. Sinonasal discharge was aseptically taken examined and sent for microscopy, culture, and sensitivity. Further investigations such as $\mathrm{x}$ ray, computerized tomographic scan of the paranasal sinuses were requested based on clinical findings. Lund-Mackay ct Scoring was applied on rhinosinusitis on the paranasal sinuses CT scans for the disease severity or presurgical evaluation. The right or left sinuses were respectively divided into six portions, including maxillary sinus, anterior ethmoid sinuses, posterior ethmoid sinuses, sphenoid sinus, frontal sinus, and ostiomeatal complex. The severity of sinus mucosal inflammation or fluid accumulation for the above six portions were unilaterally and bilaterally summed to respectively give separate unilaterally and bilaterally total Lund-Mackay ct Scoring values.

All the patients were educated based on the findings and the line of management of rhinosinusitis. Patient were then managed medically, surgically or combined. The patient's treatments were determined by the findings. Participant was followed up in the ear, nose and throat clinic for possible outcome and complications. In this study we adopted the symptoms-based diagnosis of rhinosinusitis was made. Whenever the patients had 2 major symptoms or 1 major and 2 minor symptoms diagnosis of rhinosinusitis was made.. The 4 major rhinosinusitis symptoms were nasal obstruction/blockage/congestion, nasal discharge (anterior/posterior or postnasal drip, which may be purulent), facial pain/pressure (forehead/nasal/eye), and reduction or loss of smell. The minor rhinosinusitis symptoms were headaches, fever (other than acute rhinosinusitis), halitosis, fatigue, dental pain, cough, and ear pain/pressure/fullness, besides nasal endoscopy and/or computerized tomographic scan 6. All data obtained were documented, collated and analysed. The data analysis was done by using SPSS version 18. The analyzed data were expressed by simple descriptive methods, tables, bar chart and pie chart.

Results

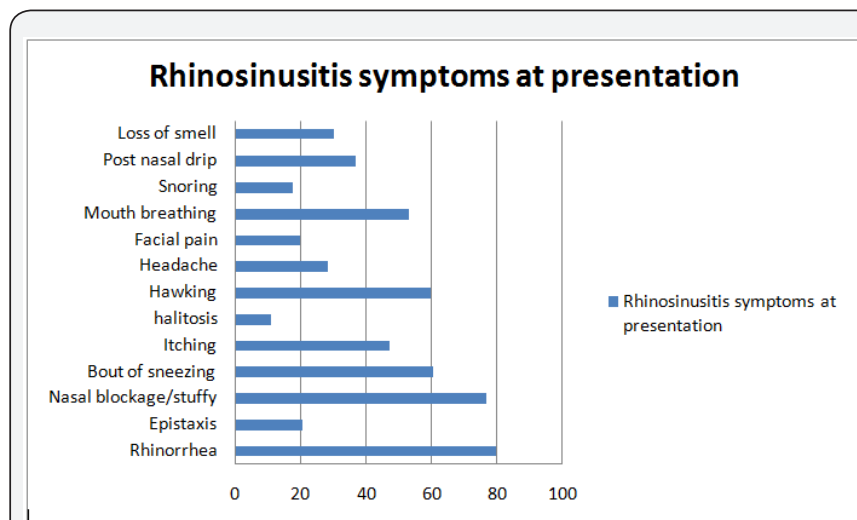

Figure 1: Rhinosinusitis symptoms at presentation.

A total 4341 patients were seen in ear, nose and throat clinic over same period. There were 523 consented patients with diagnosis of 


\section{Global Journal of Otolaryngology}

rhinosinusitis that met the inclusion criteria and were enrolled into the study. The prevalence of rhinosinusitis in this study was $8.3 \%$. There were 270 (51.6\%) males and 253 (48.4\%) females. Male to Female ratio was 1:1. Table 1 showed the age group distribution of the patients. They are evenly represented with peak age group at third decade (21-30). Major presenting complaints were 417 (79.7\%) catarrh/rhinorrhea/nasal discharge, 402 (76.9\%) nasal obstruction/stuffiness and 249 (47.6\%) bouts of sneezing. Less common presenting complaints were $58(11.1 \%)$ halitosis and $92(17.6 \%)$ snoring. This is illustrated in Figure 1. On clinical examination of the nose the major findings were bluish edematous nasal mucosa 381 (72.8\%), enlarged turbinate 351 (67.1\%) and reduced nasal patency 277 (52.9\%). Figures 2 \& 3 illustrated the presenting signs of the patients.

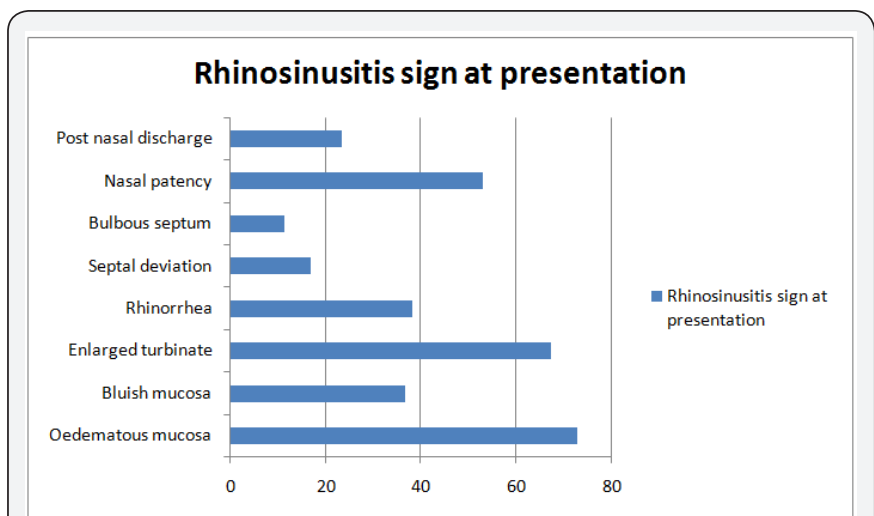

Figure 2: Rhinosinusitis signs at presentation.

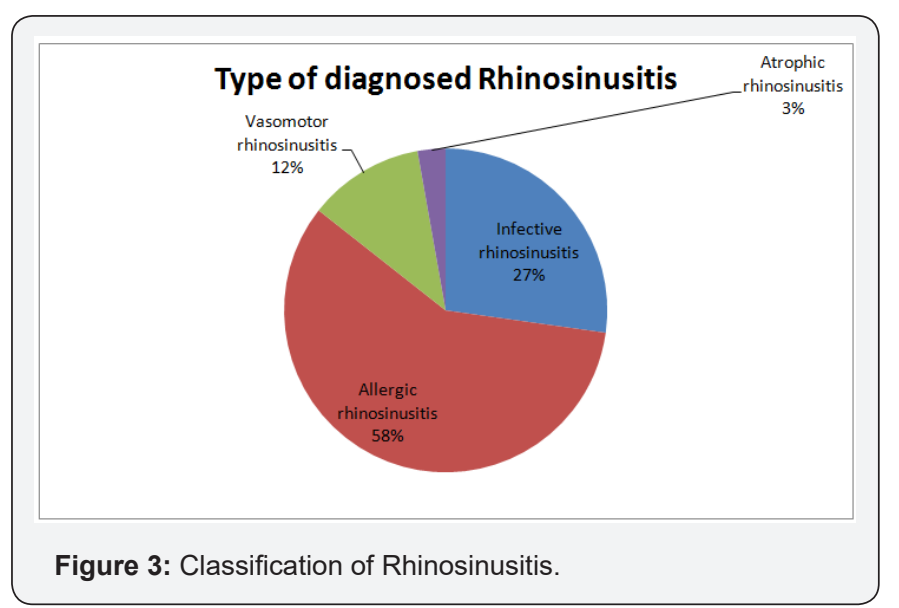

Table 1: Age distribution of rhino sinusitis patients.

\begin{tabular}{|c|c|c|}
\hline Age group in years & Number & Percentage (\%) \\
\hline $1-10$ & 13 & 13 \\
$11-20$ & 75 & 75 \\
$21-30$ & 161 & 161 \\
$31-40$ & 100 & 100 \\
$41-50$ & 121 & 121 \\
$51-60$ & 36 & 36 \\
61 and above & 17 & 17 \\
\end{tabular}

Majority 406 (77.6\%) of the patients presented at hospital as chronic rhinosinusitis after three months of onset of symptoms. Then 117 (22.4\%) others presented as acute rhinosinusitis before three months usually less than 6 weeks for acute. Rhinosinusitis in this study has resulted in affectation of quality of life in 424 $(81.0 \%)$ of the studied population. This is showed in Tables 2 \& 3 . The pattern of quality of life affected were: sleep disturbances 196 (37.4\%), bodyache 128 (24.5\%), general health $84(16.1 \%)$, psychological disorders $32(6.2 \%)$, social functioning 169 (32.4\%), changes in mood 71 (13.5\%), depression 41 (7.8\%), anxiety 66 (12.6\%), fatigue 25 (4.8\%) and sexual dysfunction 38 (7.2\%). Major comorbid illnesses among the studied population were nasal polyps $130(24.8 \%)$ and asthma 102 (19.5\%). Less common comorbid illnesses were diabetes mellitus 9 (1.7\%) and hypertension 7 (1.4\%) (Table 2).

Table 2: Rhinosinusitis co-morbid illnesses.

\begin{tabular}{|c|c|c|}
\hline Comorbid illnesses & Number & Percentage (\%) \\
\hline Asthma & & \\
Foreign body & 102 & 19.5 \\
Nasal mass & 25 & 4.7 \\
Frontoethmoidal & 86 & 16.4 \\
mucocele & 14 & 2.6 \\
Adenotonsillar & 15 & 2.9 \\
enlargement & 130 & 24.8 \\
Nasal polyps & 9 & 1.7 \\
Diabetes mellitus & 7 & 1.4 \\
Hypertension & & \\
\hline
\end{tabular}

Table 3: Quality of life among the rhinosinusitis patient's.

\begin{tabular}{|c|c|c|}
\hline Quality of life & Number & Percentage (\%) \\
\hline sleep disturbances & 196 & 37.4 \\
Bodyache & 128 & 24.5 \\
General health & 84 & 16.1 \\
Psychological & 32 & 6.2 \\
disorders & 169 & 32.4 \\
Social functioning & 98 & 18.7 \\
Work absenteeism & 91 & 17.4 \\
School absenteeism & 71 & 13.5 \\
Changes in mood & 41 & 7.8 \\
Depression & 66 & 12.6 \\
Anxiety & 25 & 4.8 \\
Fatigue & 38 & 7.2 \\
Sexual dysfunction & & \\
\hline
\end{tabular}

Associated complications of the rhinosinusitis among the studied population were mainly pharyngitis $184(35.1 \%)$ and otitis media 167 (31.9\%) Less common complications seen were orbital complication (cellulitis) 35 (6.7\%) and bronchopneumonia $38(7.2 \%)$. This is illustrated in Table 4. Microscopic, culture and sensitivity was requested for participants when based on patient's condition. There was no growth in $9(1.7 \%)$ of the nasal mucous 
taken. There were growths of streptococcus so 126 (24.1\%), Staphylococcus aureus 97 (18.5\%) and Hemophilus influenzae 61 $(11.7 \%)$ were recorded. In this study of rhinosinusitis radiologic request were made based on the patient's condition. This included x-rays and CT scan only 353 (67.4\%) had radiological examination Table 4: Complications of Rhinosinusitis in the patients.

\begin{tabular}{|c|c|c|}
\hline Complications & Number & Percentage (\%) \\
\hline Orbital complication & 35 & 6.7 \\
Headache & 148 & 28.3 \\
Otitis media & 167 & 31.9 \\
Pharyngitis & 184 & 35.1 \\
Pneumonia & 38 & 7.2 \\
\hline
\end{tabular}

Table 5: Lund-Mackay scores distributions of the right and left paranasal sinuses.

\begin{tabular}{|c|c|c|c|c|c|c|}
\hline Paranasal sinuses & Right 0 & Right 1 & Right 2 & Left 0 & Left 1 & Left 2 \\
\hline $\begin{array}{c}\text { Frontal sinus } \\
\text { Maxillary sinus } \\
\text { Anterior ethmoid } \\
\text { sinus } \\
\text { Posterior ethmoid } \\
\text { sinus } \\
\text { Ostiomeatal } \\
\text { complex } \\
\text { Sphenoid sinus }\end{array}$ & $\begin{array}{l}87.6 \% \\
55.8 \% \\
72.6 \% \\
74.5 \% \\
85.3 \% \\
96.4 \%\end{array}$ & $\begin{array}{c}8.1 \% \\
26.5 \% \\
15.7 \% \\
14.1 \% \\
2.3 \%\end{array}$ & $\begin{array}{c}4.3 \% \\
17.7 \% \\
11.7 \% \\
11.4 \% \\
14.7 \% \\
1,3 \%\end{array}$ & $\begin{array}{c}4.3 \% \\
17.7 \% \\
11.7 \% \\
11.4 \% \\
14.7 \% \\
1,3 \%\end{array}$ & $\begin{array}{c}2.1 \% \\
22.6 \% \\
15.6 \% \\
8.8 \% \\
2.1 \%\end{array}$ & $\begin{array}{c}2.1 \% \\
22.6 \% \\
15.6 \% \\
8.8 \% \\
2.1 \%\end{array}$ \\
\hline
\end{tabular}

Nasal cavity shown enlarged turbinate and septal deviation. Paranasal sinuses revealed haziness, air-fluid levels, mucosal thickening, and polyps and so on. The orders of paranasal sinuses affectation were maxillary, ethmoid, frontal and sphenoid sinuses. This is illustrated in Table 5. Treatment offered to rhinosinusitis patients were medical, surgical or combined therapy. Medical therapy in form of was offered to 399 (76.3\%) while 124 (23.7\%) had surgical treatment types. Combined therapy given to 118 (22.6\%) of the participants. Remarkable improvement was noticed by $456(87.2 \%)$ of the studied population while the remaining do not noticed remarkable improvement following one week therapy.

\section{Discussion}

Rhinosinusitis is a very common sinonasal disease seen in Otorhinolaryngological practice worldwide, and Ekiti community is not excluded. This disorder is characterized by inflammation of the mucosa of the nose and paranasal sinuses. The prevalence of rhinosinusitis of $8.3 \%$ is very low compared to findings among Caucasians $[13,14]$. Rhinosinusitis has no predilection for age but the peak age group was 21 to 30 years age group. This modal age group for rhinosinusitis coincides with active and very productive age group. It was also noticed that the lowest prevalence in this study was at the extreme of age groups. This may likely be due to underdevelopment of the sinuses in ages 1 to 10 years. Elderly adaptation to chronic rhinosinusitis may be a factor to their low presentation in this study. In clinical presentation of rhinosinusitis the major presentation in this study was rhinorrhea over other done, while 170 (32.6\%) could not. The radiological findings on the paranasal sinuses were normal in $72(13.7 \%)$ while the remaining $451(86.3 \%)$ revealed different form of abnormalities in the nasal cavity and paranasal sinuses. presenting complaints. This finding is different from findings in other research work [15].

On nasal examination, oedematous nasal mucosa was also the commonest nasal findings. This is as a result of inflammatory reaction of sinonasal mucosa to the offending agent. This study revealed allergic rhinosinusitis as the commonest, followed by infective rhinosinusitis as the cause of rhinosinusitis in this study. Allergic rhinosinusitis is recurrent, chronic, runs in the family and non-communicable as in previous study [16]. This study further revealed chronic rhinosinusitis to be commoner than acute rhinosinusitis as found in previous study. This may be due to common cases of poorly treated acute rhinosinusitis, high prevalence of allergic. Commonest comorbid illnesses associated with rhinosinusitis in this study were asthma and nasal polyps. Asthma may be as a result of similar IgE hypersensitivity reaction like allergic rhinosinusitis. Nasal polyp's cause's mucous stasis with subsequent infection leads to or worsen rhinosinusitis. Pharyngeal extension of rhinosinusitis leads to the commonest pharyngeal complication seen in this study and previous study [17].

This study revealed affectation of quality of life of rhinosinusitis sufferers with affectation of all aspect of life. Majority of the studied population had sleep disturbances and social functioning. This is resultant effect of the symptomatology of nasal blockage/stuffiness, nasal discharge and bout of sneezing. Some studies revealed similar findings [17-24]. The commonest microorganism's growth recorded in this study was Streptococcus sp. This is different from growth 
recorded in other studies [25-30]. Radiological findings on nasal cavity revealed erection and enlargement of turbinate's leading to blockage of the ostia of the paranasal sinuses. Furthermore maxillary sinus was found to be the most commonly affected of the four sinuses. This is similar to findings in previous studies [31-38].

In this study all patients had initial medical treatment to eliminate infection or any offending agent and restoration of function. Medical management involves the use of steam inhalation, systemic antibiotics, nasal steroid spray, systemic decongestant, topical nasal decongestants, and analgesics. When medical intervention failed to cure or there was residual pathology, surgical management is indicated. The surgery involves removal of the pathology and restoration of sinuses drainage. Majority of the studied population responded to medical treatment while few had surgical intervention and this finding is similar to the results of other studies [39-47].

\section{Conclusion}

In rhinosinusitis majority of cases present as chronic diseases in the study population. This condition usually has comorbid illnesses, complications and affects quality of life of the patients at presentation. Difficult or complicated cases should be promptly referred to Otorhinolaryngologist for early intervention.

\section{References}

1. Ressel G (2004) Sinus and Allergy Health Partnership releases report on adult chronic rhinosinusitis. Am Fam Physician 69(9): 2248-2249.

2. Kern RC, Conley DB, Walsh W, Chandra R, Kato A, et al. (2008) Perspectives on the etiology of chronic rhinosinusitis: An immune barrier hypothesis. Am J Rhinol 22(6): 549-559.

3. Adoga AA, Nuhu DM (2011) The Epidemiology and Economic Impact of Rhinosinusitis in Jos, North-central Nigeria. Journal of Clinincal Research Bioethic 2: 11-16.

4. Deepthi NV, Menon UK, Madhumita K (2012) Chronic rhinosinusitisan overview. Amrita J Med 8(1): 1-44.

5. Dunmade AD, Afolabi OA, Alabi BS, Busari SS, Koledoya AO (2012) Intra-antral application of an anti-fungal agent for recurrent maxillary fungal rhinosinusitis:A case report. Journal of Medical Case Report 20(6): 245-248.

6. Awuah P, Duah IM (2012) Results of orbital cellulitis treatment. Journal of Natural Sciences Research 2: 91-5.

7. Adeji TO, Olaosun AO, Tobih JE, Adejumo OO (2013) Sinogenic orbital infections in a Nigerian Teaching Hospital. Advenced Tropical Medecin Publication Health international 3(4): 87-100.

8. Chandramani P, Ashok S (2011) Allergic Aspergillus Sinusitis and its association with allergic bronchopulmonary aspergillosis. Asian pacific Allergy 1(3): 130-137.

9. Ishitoya J, Sakuma Y, Tsukuda M (2010) Eosinophilic Chronic Rhinosinusitis in Japan. Allergolint 59(3): 239-245.

10. Bhattacharyya $\mathrm{N}$ (2006) Clinical and symptom criteria for the accurate diagnosis of chronic rhinosinusitis. Laryngoscope 116: 1-22.

11. Meltzer EO, Hamilos DL (2011) Rhinosinusitis diagnosis and management for the clinician: A synopsis of recent consensus guidelines. Mayo Clin Proc 86(5): 427-443.
12. Kolo ES (2012) The role of plain radiographs in the diagnosis of chronic maxillary rhinosinusitis in adults. African Health Sciences 12(4): 459-463.

13. Fokkens WJ, Lund VJ, Mullol J (2012) European Position Paper on rhinosinusitis and nasal polyps 2012. Rhinol Suppl 23: 1-298.

14. Fokkens W, Lund V, Mullol J (2007) European Position Paper on Rhinosinusitis and Nasal Polyps group. European position paper on rhinosinusitis and nasal polyps 2007. Rhinol Suppl 20: 1-136.

15. Soler ZM, Mace J, Smith TL (2008) Symptom-based presentation of chronic rhinosinusitis and symptom-specific outcomes after endoscopic sinus surgery. Am J Rhinol 22(3): 297-301.

16. Fasunla JA, Nwaorgu OGB (2011) Adult chronic rhinosinusitis: spectrum of clinical features and management in a tertiary health institution and literature review. East and Central African Journal of Surgery 16(1).

17. Alt JA, DeConde AS, Mace JC, Steele TO, Orlandi RR, et al. (2015) Quality of Life in Patients With Chronic Rhinosinusitis and Sleep Dysfunction Undergoing Endoscopic Sinus Surgery: A Pilot Investigation of Comorbid Obstructive Sleep Apnea. JAMA Otolaryngol Head Neck Surg 141(10): 873-881.

18. Pablo Pinillos Marambaia, Manuela Garcia Lima, Kleber Pimentel Santos, Amaury de Machado Gomes, Milena Magalhães de Sousa, et al. (2013) Evaluation of the quality of life of patients with chronic rhinosinusitis by means of the SNOT-22 questionnaire. Braz J Otorhinolaryngol 79(1): 54-58.

19. Schatz Michael, Zeiger Robert S, Chen Wansu, Yang Su Jau, Stanford Richard H, et al. (2012) A comparison of the psychometric properties of the Mini-Rhinitis Quality of Life Questionnaire and the Rhinitis Control Assessment Test. American Journal of Rhinology \& Allergy 26(2): 127-133.

20. Chan Y, Kuhn FA (2009) An update on the classifications, diagnosis and treatment of rhinosinusitis. Curr Opin Otolaryngol Head Neck Surg 17(3): 204-208.

21. Stewart M, Ferguson B, Fromer L (2010) Epidemiology and burden of nasal congestion. Int J Gen Med 3: 37-45.

22. Smith WM, Davidson TM, Murphy C (2009) Regional variations in chronic rhinosinusitis, 2003-2006. Otolaryngol Head Neck Surg 141(3): 347-352.

23. Da Lilly Tariah OB (2006) Pattern of clinical features of chronic simple rhinosinusitis in Port-Harcourt. Niger J Clin Pract 9(2): 142-146.

24. Poetker DM, Smith TL (2007) Adult chronic rhinosinusitis: surgical outcomes and the role of endoscopic sinus surgery. Curr Opin Otolaryngol Head Neck Surg 15(1): 6-9.

25. Revai K, Dobbs LA, Nair S, Patel JA, Grady JJ, et al. (2007) Incidence of acute otitis media and sinusitis complicating upper respiratory tract infection: The effect of age. Pediatrics 119(6): 1408-1412.

26. Brook I, Gober AE (2007) Frequency of recovery of pathogens from the nasopharynx of children with acute maxillary sinusitis before and after the introduction of vaccination with the 7-valent pneumococcal vaccine. Int J Pediatr Otorhinolaryngol 71(4): 575-579.

27. Brook I, Foote PA, Hausfeld JN (2008) Increase in the frequency of recovery of meticillin-resistant Staphylococcus aureus in acute and chronic maxillary sinusitis. J Med Microbiol 57 (8): 1015-1017.

28. Afolabi OA, Alabi BS, Omokanye HK, Ayodele SO, Segun-Busari S, et al. (2017) Ologe Management and Outcome of Rhinosinusitis in Nigeria. OTO Open: The Official Open Access Journal of the American Academy of Otolaryngology-Head and Neck Surgery Foundation. 


\section{Global Journal of Otolaryngology}

29. Eziyi JAE, Amusa YB, Nwawolo CC (2014) The prevalence of nasal diseases in Nigerian school children. Journal of Medicine and Medical Sciences 5(4): 71-77.

30. Ogah SA, Ogah JI, Enesi IE, Oseji DI (2017) Aerobic bacteriology of throat swabs in adult patients with chronic rhinosinusitis in Lokoja, Kogi state, Nigeria Nig. J Pure \& Appl Sci 30(1): 2965-2970.

31. Ezeanolue BC, Aneke EC, Nwagbo DF (2000) Correlation of plain radiological diagnostic features with antral lavage results in chronic maxillary sinusitis. West Afr J Med 19(1): 16-18.

32. Oyinloye OI, Akande JH, Alabi BS, Afolabi OA (2013) Incidental paranasal sinus abnormality on cranial computed tomography in a Nigerian population. Ann Afr Med 12(1): 62-64.

33. Ahmad BM, Tahir AA (2000) Rhinosinusitis in North Eastern Nigeria: clinico-radiologic findings. Niger J Med 9: 21-23.

34. Ologe FE, Olatunji AA (2003) Radiographic pattern of chronic sinusitis in Ilorin, Nigeria. Niger Postgrad Med J 10(4): 205-207.

35. Kalogjera L (2011) Rhinitis in adults. Acta Med Croatica 65(2): 181 187.

36. Shin SH, Ye MK, Lee YH (2007) Fungus culture of the nasal secretion of chronic rhinosinusitis patients: seasonal variations in Daegu, Korea. Am J Rhinol 21(5): 556-559.

37. Lund VJ, Mackay IS (1993) Staging in rhinosinusitis. Rhinology 31(4): 183-184.

38. Maduforo CO, Ibinaiye P, Onotai LO (2013) Plain radiographic Pattern of Chronic Sinusitis: Our recent experience. Int J Med Med Sci 3(1): 317-320.

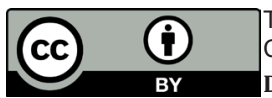

This work is licensed under Creative Commons Attribution 4.0 License

DOI: $10.19080 /$ GJO.2018.12.555847
39. Watelet JB, Eloy PH, Van Cauwenberge PV (2007) Drug management in chronic rhinosinusitis: Identification of the needs. Ther Clin Risk Manag 3(1): 47-57.

40. Smith TL, Batra PS, Seiden AM, Hannley M (2005) Evidence supporting endoscopic sinus surgery in the management of adult chronic rhinosinusitis: a systematic review. Am J Rhinol 19(6): 537-543.

41. Mantovani K, Bisanha AA, Demarco RC, Tamashirom E, Martinez R, et al. (2010) Maxillary sinuses microbiology from patients with chronic rhinosinusitis. Brazilian. Journal of otorhinolaryngology 76(5): 548551.

42. Okafor BC (1983) Otolaryngology in South Eastern Nigeria 11 Pattern of diseases of the nose. Niger Med J 13: 21-9.

43. Bhatia PC, Varugese R (1987) Pattern of Otolaryngological diseases in Jos community. Niger Med J 17: 67-73.

44. Nwawolo CC (1997) Hazards of maxillary antral washout. Nig Postgrad Med J 4: 123-126.

45. Hamilos DL (2011) Chronic rhinosinusitis: Epidemiology and medical management. Journal of Allergy \& Clinical Immunology 128(4): 693707.

46. Ogunleye AO, Nwaorgu OG, Lasisi AO, Ijaduola GT (1999) Trends of sinusitis in Ibadan. West Afr J Med 18(4): 298-302.

47. Masood A, Moumoulidis I, Panesar J (2007) Acute rhinosinusitis in adults, an update on current management. Postgrad Med J 83(980): 402-408.

\section{Your next submission with Juniper Publishers} will reach you the below assets

- Quality Editorial service

- Swift Peer Review

- Reprints availability

- E-prints Service

- Manuscript Podcast for convenient understanding

- Global attainment for your research

- Manuscript accessibility in different formats ( Pdf, E-pub, Full Text, Audio)

- Unceasing customer service

Track the below URL for one-step submission https://juniperpublishers.com/online-submission.php 